\title{
Multidisciplinary Cooperation Alleviates Postoperative Pain after Elective Craniotomies: A Prospective Randomized Controlled Study of Neurosurgical Enhanced Recovery After Surgery (ERAS) program
}

Liang Qu

Fourth Military Medical University

Yuan Wang

FMMU

Bolin Liu

FMMU

Haitao Zhang

FMMU

Zhengmin $\mathrm{Li}$

FMMU

Jiangtao Niu

FMMU

Binfang Zhao

FMMU

Tianzhi Zhao

FMMU

Xue Jiang

FMMU

Lin Ye

FMMU

Lanfu Zhao

FMMU

Wenhai Lv

FMMU

Yufu Zhang

FMMU

Tao Zheng

FMMU 
Yafei Xue

FMMU

\section{Lei Chen}

FMMU

Long Chen

FMMU

Yingxi Wu

FMMU

Mingjuan Li

FMMU

\section{Lin Ma}

FMMU

Ruigang Li

FMMU

Juan Li

FMMU

Jing Yan

FMMU

Shasha Wang

FMMU

Hui Zhao

FMMU

Xude Sun

FMMU

Guodong Gao

FMMU

Xuelian Wang

FMMU

Yan Qu

FMMU

Shiming He ( $\square$ 693460235@qq.com )

Fourth Military Medical University

Research article

Keywords: Enhanced recovery after surgery (ERAS), neurosurgery, elective craniotomy, pain management, outcomes

Posted Date: January 7th, 2020 
DOI: https://doi.org/10.21203/rs.2.20215/v1

License: (c) (1) This work is licensed under a Creative Commons Attribution 4.0 International License. Read Full License 


\section{Abstract}

Objective: To prospectively evaluate the efficacy of neurosurgical enhanced recovery after surgery (ERAS) protocol on the management of postoperative pain after elective craniotomies.

Methods: This randomised controlled trial was conducted in the neurosurgical center of Tangdu Hospital (Fourth Military Medical University, Xi'an, China). A total of 129 patients undergoing craniotomies between October 2016 and July 2017 were enrolled in a randomized clinical trial comparing ERAS protocol and conventional care. The primary outcome was the postoperative pain score assessed by a verbal numerical rating scale (NRS).

Results: Patients in the ERAS group had a significant reduction in postoperative pain score on POD 1 compared to patients in the control group (mean NRS 3.12 vs. 4.44 , OR $0.0968,95 \% \mathrm{Cl} 0.3299$ to $2.317, \mathrm{p}$ $=0.010$ ). More patients $(n=44,68.8 \%)$ in the ERAS group experienced mild pain (NRS: 1 to 3 ) on POD1 compared with patients $(n=23,35.4 \%)$ in the control group $(p<0.05)$. A significant reduction in pain score was observed on POD 2 and POD 3 in the ERAS group compared with that in the control group (POD2: mean NRS 2.85 vs. 4.32 , OR $0.2628,95 \% \mathrm{Cl} 0.5619$ to $2.379, \mathrm{p}=0.002$. POD3: mean NRS 2.32 vs. 4.03 , OR $0.1468,95 \% \mathrm{Cl} 0.9537$ to $2.458, \mathrm{p}<0.001$, respectively). In addition, the median postoperative length of hospital stay was significantly decreased with the incorporation of ERAS protocol compared to the controls (ERAS: 4 days, control: 7 days, $P<0.001$ ).

Conclusion: Implementation of the neurosurgical ERAS protocol for elective craniotomy patients have significant benefits in alleviating postoperative pain and enhancing recovery after surgery compared to the conventional care. Further evaluation of this protocol in larger, multi-center studies is warranted.

\section{Introduction}

With the increasing public expectations for high quality and efficient healthcare, there is a trend that more clinicians, especially neurosurgeons, are making efforts to optimize patient outcomes by addressing pre-, peri-, and post-operative factors ${ }^{1,2}$. Enhanced recovery after surgery (ERAS) protocols primarily aim at optimizing outcomes, increasing patient satisfaction, and reducing health care costs ${ }^{3}$. In the recent decades, a number of standardized ERAS protocols have been implemented across the entire perioperative period ${ }^{4-8}$. Conventional perioperative care protocol is typically related to extensive preoperative preparation, significant surgical stress and prolonged time of functional recovery. Excessive adverse effects may increase the risks of cerebrovascular complications, nutrient malabsorption and delayed convalescence in surgical patients ${ }^{9}$. On the other hand, with the development of perioperative pathophysiology, the concept of ERAS has been established to standardize clinical practice, improve functional capacity after surgery, speed up the patients' rehabilitation, reduce postoperative length of stay (LOS), reduce medical cost, and improve the patients' satisfaction ${ }^{10,11}$. 
When making the decision on whether to adopt a new comprehensive protocol in elective craniotomies, the neurosurgeons must consider the quality \& safety of the procedure and risk tolerance. Moreover, the quality improvement methods should raise the degree of patients' perceived comfortableness. For elective craniotomies, the key indicator is postoperative pain. Acute pain is common during the postoperative period, and is associated with complications and adverse outcomes. To date, there is controversy in the literature regarding the evaluation of pain and its intensity in patients undergoing neurosurgical procedures ${ }^{12,13}$. Moreover, different types of pain therapy have been advocated for the same neurosurgical procedure based on clinicians' personal or institutional preference ${ }^{13-15}$. To our knowledge, no well designed study has been conducted to compare the effect on perioperative verbal NRS scores of ERAS program with the conventional surgery protocol.

Although there are a few studies to evaluate new protocols for elective spinal and peripheral nerve surgery, the quality and safety outcomes of those programs have not been well described ${ }^{9,10}$. Recently, our group have developed a multi-disciplinary neurosurgical ERAS protocol for craniotomies based on the best available evidence ${ }^{1,16,17}$.Our teams included neurosurgeons, anesthetists, residents, operating room nurses, neurophysiologist, dieticians, statistician and other non-medical staff. This ERAS approach links patients, clinicians and scientists in a new way, that aims to make improvements in healthcare cost, quality and timeliness. By implementing an evidence-based neurosurgical ERAS protocol among 129 patients undergoing craniotomies at the Neurosurgical center of Tangdu Hospital, Fourth Military Medical University (Xi'an, China) we evaluated the efficacy of improvement on postoperative pain control by e analyzing data on pain intensity and pain characteristics.

\section{Methods}

The study was approved by the Ethical Committee of Tangdu Hospital at the Fourth Military Medical University, and this study has been registered in the Chinese Clinical Trial Registry with registration number ChiCTR-INR-16009662.

\section{The intervention: ERAS protocol and conventional protocol}

All patients were randomised 1:1 to receive ERAS protocol and conventional protocol. The neurosurgical ERAS protocol for patients undergoing elective craniotomy was reported in previous study. The ERAS group was instructed to follow the procedure of ERAS protocol by neurosurgical ERAS record checklist and to perform the individual items as much as possible (Supplementary file 1 and Supplementary file 2).. The conventional protocol group was implemented according to individual discretions of the neurosurgeons and anesthetists, based on routine institutional neurosurgical postoperative protocols (Supplementary file 3).. Patients were followed up till 4 months after hospital discharge or death.

\section{Compliance with ethical standards}


Informed consent was achieved from all individual participants or their legal representatives included in this study. The analysis and usage of patient information for this study was approved by the Ethical Committee of Tangdu Hospital. And the methods were carried out in accordance with the approved guidelines. This randomized control trial (RCT) was registered at Chinese Clinical Trial Registry (Registration date: October 27, 2016, http://www.chictr.org.cn/showproj.aspx?proj = 16480).

\section{Study participants}

From October 2016 to July 2017, 129 patients aged from 18 to 65 years, who were admitted for elective craniotomies at Department of Neurosurgery, Tangdu Hospital were enrolled for this study.

The inclusion criteria were as follows: (1) Patients with single intracranial lesion and medically eligible for elective craniotomy; (2) Age between 18-65 years; (3) Patients who are able to communicate well with the medical staff; (4) Patients who understand and sign the Informed Consent, with good compliance in the study.

The exclusion criteria comprised of (1) non-brain tumor patients, such as severe craniocerebral injury leading to bilateral mydriasis, unstable vital signs; (2) children (patients less than 18 years), awake craniotomy; (3) patients with severe spinal cord shock; (4) other trauma caused by preoperative cardiac arrest, combined with severe limb fractures or thoracic and abdominal injury; (5) infection or inflammation in the surgical area; (6) serious comorbidities (blood system, respiratory system, digestive system, etc.) patients; (7) patients with severe heart disease (such as coronary heart disease, myocardial infarction, etc.); (8) Patients with ULN and / or renal function ( $\mathrm{Cr}$ ) > 1.5 times ULN with liver function (ALT, AST) > 2 times; (9) patients with mental illness or severe mental illness; (10) Women who have a childcare plan within 6 months of pregnancy or breastfeeding; (11) Other patients who were considered unsuitable for inclusion in the study.

\section{Patient enrolment}

Research assistants (RAs) consulted duty nurses daily to identify all new admissions as potential study participants. After confirming eligibility and obtaining consent, RAs collected patient characteristics data including demographic information (age, sex), admission diagnosis, preoperative co-morbidity status (American association of anesthesiologists grades, ASA grades) and other presenting physical characteristics (smoking, diabetes, motion sickness, hypertensive disease, etc.). Data about the details of operations like types of operation, lesion locations (supratentorial superficial lesion, supratentorial deepseated lesion or infratentorial lesion) were also assessed. All data were collected on a secure, web-based program.

\section{Randomisation}


After obtaining informed consents, patients were prospectively randomized into two groups (1:1 ration) by simple randomization procedures (computerized random numbers) by the research coordinator. A total of 65 patients were allocated to control group who received the conventional perioperative care, whereas 64 patients were allocated to ERAS group who received care according to the neurosurgical ERAS protocol. Due to the requirement for active patient participation, it was not possible to perform the study with blinded participants and care providers. Only those who collected and assessed outcomes were blinded to the allocation.

\section{Outcome measurements}

The primary outcome of this study was the score of postoperative pain related NRS. The verbal NRS ranges from 0 to 10 (0 represents no pain and 10 represents the worst pain). Postoperative NRS of surgical site pain was assessed on postoperative day (POD) 1 and repeated daily until the patient had no complaint of pain or was discharged.

Secondary outcome measures included: (1) analgesic medication administration. The nonopioid analgesic drugs $₫$ weak opioid analgesics ( + nonopioid analgesic drugs) and strong opioid analgesics ( + nonopioid analgesic drugs) were administered for postoperative pain treatment depending on the assessment and decision of the attending team; (2) median of the total hospital length of stay from admission to discharge; (3) median of post procedure length of stay from end of procedure to discharge, and (4) total cost of hospitalization (CNY).

\section{Statistical analysis}

Data were collected during the hospitalization and at the 4-month follow-up after hospital discharge. Descriptive statistics of ERAS group and control group were compared for all relevant patient characteristics. A sample size of at least 60 patients per arm was calculated to have a power of $80 \%$ and a significance of $5 \%$. To compensate for potential dropouts, 129 patients were enrolled. Continuous data with a normal distribution were statistically tested for group differences using chi-square test and Fisher's exact text. The statistical analysis was performed with SPSS software (Ver. 19, IBM Corp., Armonk, NY). A $P$ value of $<0.05$ was considered to be statistically significant.

\section{Results}

- Baseline characteristics

A total of 129 patients ( 64 patients from ERAS group and 65 patients from control group) patients were enrolled in this study and were preoperatively randomized to one of two groups: ERAS group and control group. Patient characteristics are shown in Table 1. Demographic and clinical features were not significantly different between the intervention and control groups. All patients in both groups underwent elective craniotomies by the same experienced neurosurgical team. Final analysis compared 64 ERAS 
group patients with 65 control group patients (Figure 1).. In both groups, the proportion of female patients was higher than that of male patients, but there was no significant gender difference between two groups. The relevant details of surgery and outcomes are also shown in Table 1. There was no significant difference in categories of indications for operations. Patients who met the inclusion criteria were included in the study and presented with common neurological deficits. The location of lesions has no significant difference between the groups, and every patient went through a standardized surgical procedure as mentioned previously.

- The assessment of postoperative surgical pain

Primary outcome measurements are shown in Table 2. Patients in the ERAS group had a significant reduction in postoperative pain score on POD 1 compared to patients in the control group (mean NRS 3.12 vs. 4.44 , OR $0.0968,95 \% \mathrm{Cl} 0.3299$ to $2.317, \mathrm{p}=0.010)$. In addition, more patients $(\mathrm{n}=44,68.8 \%)$ in the ERAS group experienced mild pain (NRS: 1 to 3 ) on POD1 compared with that $(n=23,35.4 \%$ ) in the control group. Less patients $(n=18,28.1 \%)$ in the ERAS group experienced moderate pain (NRS: 4 to 7 ) on POD1 compared with that $(n=39,60.0 \%)$ in the control group. A total of $3.1 \%(n=2)$ of patients experienced severe pain (NRS: 8 to 10$)$ on POD1 in the ERAS group, while $4.6 \%(n=3)$ of patients experienced severe pain (NRS: 8 to 10) on POD1 in the control group. A significant reduction in pain score was observed on POD 2 and POD 3 in the ERAS group compared with that in the control group (POD2: mean NRS 2.85 vs. 4.32 , OR $0.2628,95 \% \mathrm{Cl} 0.5619$ to $2.379, \mathrm{p}=0.002$. POD3: mean NRS 2.32 vs. 4.03 , OR $0.1468,95 \% \mathrm{Cl} 0.9537$ to $2.458, \mathrm{p}<0.001$, respectively). The duration of pain complaint (postoperative pain duration time) was also shortened for the patients in the ERAS group compared with that in the control group $(\mathrm{p}<0.001$, Table 2$)$.. in the ERAS groupin the control groupMore patients have pain complaint for $1-2$ days in the ERAS group than control group ( $54.7 \%$ in ERAS vs. $20.0 \%$ in control, $p$ $<0.05)$, while less patients has pain complaint for 2-3 days in the ERAS group than control group $(21.9 \%$ in ERAS vs. $40.0 \%$ in control, $p<0.05)$.

- Analgesic medication administration and other secondary outcomes

The analgesics were administered to relieve postoperative pain depending on the assessment and decision of the attending team. The analgesics were divided into three categories (WHO classification of pain treatment, Table 3).. The analgesic medication used in the ERAS group and control group are shown in Table 4. In general, the number of patients receiving WHO Class I - WHO Class III medication was not significantly different between two groups (ERAS group: $n=15,23.4 \%$ vs. control group: $n=22,33.8 \%, P$ $=0.356$ ). On POD 1 , the percentage of patients receiving WHO Class I analgesic medication was $14.1 \%$ in the ERAS group vs. that of $12.3 \%$ in the control group. The percentage of patients receiving WHO Class II analgesic medication was $4.7 \%$ in the ERAS group vs. that of $13.8 \%$ in the control group. The number of patients receiving WHO Class III analgesic medication was $4.7 \%$ in the ERAS group vs. that of $7.7 \%$ in the control group.

Other secondary outcome measurements are shown in Table 4. The median of total hospital LOS was significant reduced from 13 days in the control group to 10 days in the ERAS group $(P=0.004)$. The 
median of postoperative LOS was also significant reduced from 7 days in the control group to 4 days in the ERAS group $(P<0.001)$. In addition, the total cost of hospitalization was RMB 52424 (range: 33652$118965)$ in the ERAS group and RMB 64462 (range: 39973-141216) in the control group $(P<0.001)$.

- Postoperative Complications and Re-admission

Postoperative complications are listed in Table 5.9 patients (14.1\%) in the ERAS group and 14 patients $(21.5 \%)$ in the control group had postoperative fever of up to $38^{\circ} \mathrm{C}(\mathrm{p}=0.358)$. However, their temperature returned to normal within 48 hours postoperatively after removal of urinary and central venous catheters. Three patients in the ERAS group and 2 patients in the control group had postoperative seizure $(\mathrm{p}=$ 0.680 ). None of the patients had significantly raised intracranial pressure, recraniotomy, mental status changes (needs for emergent imaging), diabetes insipidus and toxic epidermal necrolysis (due to phenytoin) in the ERAS group. Four patients (6.3\%) in the ERAS group and 3 patients (4.6\%) in the control group were noted to have blood sugar levels of $>200 \mathrm{mg} / \mathrm{dL}$ intraoperatively $(p=0.718)$, and this trend persisted for 3 days postoperatively, warranting the use of short-acting insulin therapy. Ten patients (15.6\%) in the ERAS group and 18 patients $(27.7 \%)$ in the control group had nausea (moderate to severe) $(p=0.135)$. Ten patients $(15.6 \%)$ in the ERAS group and 20 patients $(30.8 \%)$ in the control group had nausea (moderate to severe) $(p=0.060)$. And none of the patients in the two groups had re-admission within the 4-month follow-up period.

\section{Discussion}

In order to assess the satisfactory quality of ERAS protocol for elective craniotomies, we analyzed data on pain intensity and pain character among 129 patients undergoing craniotomy with the implementation of the ERAS protocol vs. conventional protocol. Our results highlighted a program of multidisciplinary cooperation that could alleviate postoperative pain, reduce total hospital LOS and postoperative LOS, and reduce the total cost of medical care.

Craniotomy is a relatively common surgical procedure with a high incidence of postoperative pain ${ }^{3}$. Development of standardized pain management and ERAS protocols are necessary and crucial to optimize patient-reported outcomes and reduce health care costs ${ }^{1,3}$. The most frequent ERAS program for pain management depended on multidisciplinary cooperation, which included the efforts of neurosurgeons, anesthetists, residents, operating room nurses, neurophysiologist, dieticians and the support from family members of the patient ${ }^{1,18-20}$. However, these studies vary widely in their methodology and targeted patient populations. Some studies were limited by the generalization of implementing their recommendations in other medical institutions ${ }^{19-21}$. Recently we have implemented a new multidisciplinary, evidence-based, neurosurgical ERAS program for elective craniotomy patients in a single center ${ }^{22}$.

Optimization of pain management is a key element of ERAS protocol. Till now, there is no consensus regarding the pain management and analgesic regimen for post-craniotomy pain ${ }^{23}$. NRS is one of the 
most frequently used standardized methods to evaluate postoperative pain. In our study, in spite of the treatment of postoperative pain with analgesics, over $64.6 \%$ of the patients suffered from moderatesevere pain in the control group. This is consistent with some previous reports on the prevalence of postcraniotomy pain ${ }^{24-27}$, though nurses and physicians tried to treat the patients with best efforts. Our data showed that patients in the ERAS group had a statistically significant reduction in pain score on POD 1- POD 3 compared to patients in the control group. Moreover, the incidence of moderate pain on POD 1 reduced with the implementation of the ERAS protocol, and the patients had shorter duration of pain complaint than those in the control group (Table 2).. These results suggested that the successful implementation of the neurosurgical ERAS protocol could reduce the probability of suffering with severe pain after elective craniotomies.

There is an intense debate on whether the ERAS program reduces pain after elective craniotomies. The main finding of this study was a trend for less pain in the ERAS group patients. We speculate that the findings of reduced pain in this study may be related to some interventions included in the ERAS protocol such as smoking cessation, incisional local anesthetic blocks and additional use of acetaminophen/NSAIDs. In addition, multidisciplinary collaboration also reduces patient discomfort, speeds up wound healing, and thus reduces the degree and duration of postoperative pain. Firstly, one of the main interventions in ERAS protocol is smoking cessation. Smoking has been known to be harmful to overall health, and cigarette smoking may also associated with a worse surgical outcome and prognosis in patients undergoing craniotomy. Some studies indicate that smoking cessation may reduce postoperative complications following craniotomy ${ }^{28}$. Secondly, numerous studies have shown that scalp infiltration in patients undergoing craniotomies play crucial roles in post-craniotomy pain management ${ }^{29-33}$. Accordingly, scalp infiltration with ropivacaine or bupivacaine in the ERAS protocol may reduce the incidence and severity of postoperative pain, which has also been shown in other studies $^{23,34}$. The mechanisms underlying the beneficial effects of local anesthetic blocks include a reduction in the inflammatory and stress response associated with surgery, lower levels of angiogenesis, a decrease in the requirements of volatile anesthetics and minimization or avoidance of opioid ${ }^{35}$. Thirdly, non-opioid analgesics including acetaminophen or non-steroidal anti-inflammatory drugs were administrated according to the pain degree of patient postoperative NRS. Evidence showed that morphine was less effective for pain relief in craniotomy patients ${ }^{36,37}$. Therefore, postoperative morphine and equivalent opioids were not routinely prescribed due to their limited effect and wide ranges of side-effects for mild or moderate pain. The low dose consuming non-opioid analgesics can also reduce opioid consumption by $35-50 \%$, and alleviate persistent pain without significant adverse effects ${ }^{38-42}$. In our study, most patient showed mild pain (NRS 1-3) on POD 1, and more patients showed shortened pain duration time (1-2d) in the ERAS group (Table 2).. There was no statistical difference in analgesic medication administration between the two groups $(p=0.356$, Table 4$)$.. These results supported the effectiveness of pain management protocol in the ERAS group, which had also improved the medical recovery of patients. 
Hospital stay relies on various factors, which may be modified to a certain extent by the effect of perioperative care ${ }^{43}$. Total hospital LOS and postoperative LOS was evaluated between the ERAS group and the control group (Table 4).. C The effectiveness of the ERAS protocol was confirmed with significant shorter hospital LOS and postoperative LOS in the ERAS group. Nonetheless, postoperative LOS and total LOS are affected by several demand factors (age, sex, disease severity, complications, et al.) and supply factors (clinical methodology, local medical insurance policies, bed occupancy, and et al.) ${ }^{44,45}$. These factors needed to be considered in assessing the efficacy of an ERAS protocol in clinical trials. Future studies may incorporate interventions designed to improve the comfortableness and engagement of individualized pain management for targeted patient populations. Future multicenter clinical trials for evaluating an evidence based neurosurgical ERAS protocol also require more rigorous design and power analysis, proper calibration for multiple comparisons, and the use of better outcome measures.

In addition, the current ERAS protocol incorporates nutritional interventions including preoperative carbohydrate loading and early restoration of oral solid food postoperatively, which may have a profound impact on the enhanced recovery. Such interventions were shown to alleviate muscle loss and improve organ function such as pulmonary function in addition to improve glucose homeostasis and insulin resistance ${ }^{46,47}$. These beneficial effects may also correlate with a reduction in both hospital LOS and postoperative LOS in patients participating in an ERAS program for major surgeries including craniotomies ${ }^{47,48}$. We monitored all patients for postoperative complications and re-admission rates, and none of the patients had suffered from raised intracranial pressure, recraniotomy, mental status changes (needs for emergent imaging), diabetes insipidus and toxic epidermal necrolysis (due to phenytoin) in the ERAS group (Table 5).. However, 4 patients in the ERAS group had serial blood sugar levels $>200 \mathrm{mg} / \mathrm{dL}$ intraoperatively which lasted for 3 days postoperatively and required insulin therapy. Limited by our case number, the current results may not reflect the influences of the ERAS protocol in this respect. To summarize, the postoperative complications and re-admission rate in the ERAS group was not increased as compared to that in the control group, while postoperative pain of patients was reduced significantly.

There are several limitations of the current study. First, subgroup analysis may be needed to perform with all consecutive patients within the ERAS group and conventional care protocol. Postoperative pain management is embedded in a multidisciplinary cooperation and the impact of pain management on recovery, pain relief, and length of stay needs to be interpreted in this context. Second, though postoperative pain was significantly reduced in the ERAS group, the use of opioid analgesics was not significantly decreased in the ERAS group compared to the control group. It is possible that expectations on the part of both the patients and researchers may cause bias towards a more favorable NRS score in the ERAS group since this study was not blinded. This limitation in interpretating the results of this study should be noted. Third, little information was assessed in-depth regarding the specific characteristics of targeted patient populations, which may be investigated in further studies. As mentioned in the Methods section, the ERAS pathway has been continuously adapted and updated during the study period to avoid the bias of various perioperative care pathways and unbalanced interventions. 


\section{Conclusion}

In conclusion, we have assessed the effect of an ERAS protocol for elective craniotomies, which includes a series of interventions, on alleviating postoperative pain and enhancing recovery after surgery. The results of this study confirmed the efficacy of the ERAS protocol for pain management after elective craniotomies. Moreover, the ERAS protocol also reduced total / postoperative hospital LOS and the total cost of medical care. There is an urgent need for larger multi-center studies to further evaluate this protocol in the targeted patient population.

\section{Declarations}

\section{Acknowledgments}

Special thanks to Dr. Xingye Zhang, Dr. Jungong Jing, Dr. Yong Liu for their contributions to the medical care in the study. We appreciated Lihui Yang, Fan Yao, Ye Gao, Jing Zhang for their contributions in nursing service.

\section{Funding source}

This work was supported by China Natural Science Foundation (81572470 and 81601100 ).

\section{Contributors}

S. He, Y. Wang, Y. Qu and L. Qu contributed the conception and design of the study. S. He, L. Qu and Y. Wang wrote the frst draf. Y. Qu, G. Gao, X. Wang, H. Zhang, Z. Li, W. Lv, Y. Zhang, J. Niu, B. Zhao and T. Zhao managed the clinical work and statistics. Y. Wang, B. Liu, X. Jiang, L. Ye, L. Qu, L. Zhao, Y. Zhang, T. Zheng, Y. Xue, L. Chen and H. Zhao managed participant recruitment. S. He and Y.Qu supervised this work and edited the manuscript. All authors revised the manuscript and provided feedback and comments.

Competing interests None declared.

\section{Patient consent}

This article does not contain personal medical information about an identifiable living individual, and therefore does not require the patient's explicit consent before we can publish it.

\section{Ethics approval}

The study was approved by the Ethical Committee of Tangdu Hospital at the Fourth Military Medical University.

\section{References}


1.Wang Y, Liu B, Zhao T, et al. Safety and efficacy of a novel neurosurgical enhanced recovery after surgery protocol for elective craniotomy: a prospective randomized controlled trial. Journal of neurosurgery 2018: 1-12.

2.Nanji KC, Ferris TG, Torchiana DF, Meyer GS. Overarching goals: a strategy for improving healthcare quality and safety? BMJ Qual Saf 2013; 22(3): 187-93.

3.Vacas S, Van de Wiele B. Designing a pain management protocol for craniotomy: A narrative review and consideration of promising practices. Surgical neurology international 2017; 8: 291.

4.Cerantola $\mathrm{Y}$, Valerio $\mathrm{M}$, Persson B, et al. Guidelines for perioperative care after radical cystectomy for bladder cancer: Enhanced Recovery After Surgery (ERAS((R))) society recommendations. Clinical nutrition 2013; 32(6): 879-87.

5.Melloul E, Hubner M, Scott M, et al. Guidelines for Perioperative Care for Liver Surgery: Enhanced Recovery After Surgery (ERAS) Society Recommendations. World J Surg 2016; 40(10): 2425-40.

6.Scott MJ, Baldini G, Fearon KC, et al. Enhanced Recovery After Surgery (ERAS) for gastrointestinal surgery, part 1: pathophysiological considerations. Acta anaesthesiologica Scandinavica 2015; 59(10): 1212-31.

7.Mortensen K, Nilsson M, Slim K, et al. Consensus guidelines for enhanced recovery after gastrectomy: Enhanced Recovery After Surgery (ERAS(R)) Society recommendations. The British journal of surgery 2014; 101(10): 1209-29.

8.Thorell A, MacCormick AD, Awad S, et al. Guidelines for Perioperative Care in Bariatric Surgery: Enhanced Recovery After Surgery (ERAS) Society Recommendations. World J Surg 2016; 40(9): 2065-83.

9.Ren L, Zhu D, Wei Y, et al. Enhanced Recovery After Surgery (ERAS) program attenuates stress and accelerates recovery in patients after radical resection for colorectal cancer: a prospective randomized controlled trial. World J Surg 2012; 36(2): 407-14.

10.Kehlet $\mathrm{H}$, Wilmore DW. Multimodal strategies to improve surgical outcome. American journal of surgery 2002; 183(6): 630-41.

11.Ljungqvist O, Scott M, Fearon KC. Enhanced Recovery After Surgery: A Review. JAMA surgery 2017; 152(3): 292-8.

12.Dunbar PJ, Visco E, Lam AM. Craniotomy procedures are associated with less analgesic requirements than other surgical procedures. Anesthesia and analgesia 1999; 88(2): 335-40.

13.Klimek M, Ubben JF, Ammann J, Borner U, Klein J, Verbrugge SJ. Pain in neurosurgically treated patients: a prospective observational study. Journal of neurosurgery 2006; 104(3): 350-9. 
14.Jeffrey HM, Charlton P, Mellor DJ, Moss E, Vucevic M. Analgesia after intracranial surgery: a doubleblind, prospective comparison of codeine and tramadol. British journal of anaesthesia 1999; 83(2): 2459.

15.Stoneham MD, Cooper R, Quiney NF, Walters FJ. Pain following craniotomy: a preliminary study comparing PCA morphine with intramuscular codeine phosphate. Anaesthesia 1996; 51(12): 1176-8.

16.Ali ZS, Flanders TM, Ozturk AK, et al. Enhanced recovery after elective spinal and peripheral nerve surgery: pilot study from a single institution. Journal of neurosurgery Spine 2019: 1-9.

17.Ali ZS, Ma TS, Ozturk AK, et al. Pre-optimization of spinal surgery patients: Development of a neurosurgical enhanced recovery after surgery (ERAS) protocol. Clin Neurol Neurosurg 2018; 164: 14253.

18.Gustafsson UO, Scott MJ, Hubner M, et al. Guidelines for Perioperative Care in Elective Colorectal Surgery: Enhanced Recovery After Surgery (ERAS((R))) Society Recommendations: 2018. World journal of surgery 2019; 43(3): 659-95.

19.Patel SY, Garcia Getting RE, Alford B, et al. Improved Outcomes of Enhanced Recovery After Surgery (ERAS) Protocol for Radical Cystectomy with Addition of a Multidisciplinary Care Process in a US Comprehensive Cancer Care Center. World journal of surgery 2018; 42(9): 2701-7.

20.Parrish AB, O'Neill SM, Crain SR, et al. An Enhanced Recovery After Surgery (ERAS) Protocol for Ambulatory Anorectal Surgery Reduced Postoperative Pain and Unplanned Returns to Care After Discharge. World journal of surgery 2018; 42(7): 1929-38.

21.Kjolhede P, Bergdahl O, Borendal Wodlin N, Nilsson L. Effect of intrathecal morphine and epidural analgesia on postoperative recovery after abdominal surgery for gynecologic malignancy: an open-label randomised trial. BMJ open 2019; 9(3): e024484.

22.Wang Y, Liu B, Zhao T, et al. Safety and efficacy of a novel neurosurgical enhanced recovery after surgery protocol for elective craniotomy: a prospective randomized controlled trial. Journal of neurosurgery; 0(0): 1-12.

23.Dilmen OK, Akcil EF, Tunali Y, et al. Postoperative analgesia for supratentorial craniotomy. Clinical neurology and neurosurgery 2016; 146: 90-5.

24.Rahimi SY, Alleyne $\mathrm{CH}$, Vernier E, Witcher MR, Vender JR. Postoperative pain management with tramadol after craniotomy: evaluation and cost analysis. Journal of neurosurgery 2010; 112(2): 268-72.

25.Peon AU, Diccini S. [Postoperative pain in craniotomy]. Revista latino-americana de enfermagem 2005; 13(4): 489-95. 
26.Gottschalk A, Berkow LC, Stevens RD, et al. Prospective evaluation of pain and analgesic use following major elective intracranial surgery. Journal of neurosurgery 2007; 106(2): 210-6.

27.Mordhorst C, Latz B, Kerz T, et al. Prospective assessment of postoperative pain after craniotomy. Journal of neurosurgical anesthesiology 2010; 22(3): 202-6.

28.Lau D, Ziewacz JE, Siddiqi HK, Pelly A, Sullivan SE, El-Sayed AM. Cigarette smoking: a risk factor for postoperative morbidity and 1-year mortality following craniotomy for tumor resection. Journal of neurosurgery 2012; 116(6): 1204-14.

29.Jia Y, Zhao C, Ren H, Wang T, Luo F. Pre-emptive scalp infiltration with dexamethasone plus ropivacaine for postoperative pain after craniotomy: a protocol for a prospective, randomized controlled trial. Journal of pain research 2019; 12: 1709-19.

30.Batoz H, Verdonck O, Pellerin C, Roux G, Maurette P. The analgesic properties of scalp infiltrations with ropivacaine after intracranial tumoral resection. Anesthesia and analgesia 2009; 109(1): 240-4.

31.Song J, Li L, Yu P, Gao T, Liu K. Preemptive scalp infiltration with $0.5 \%$ ropivacaine and $1 \%$ lidocaine reduces postoperative pain after craniotomy. Acta neurochirurgica 2015; 157(6): 993-8.

32.Saringcarinkul A, Boonsri S. Effect of scalp infiltration on postoperative pain relief in elective supratentorial craniotomy with $0.5 \%$ bupivacaine with adrenaline 1:400,000. Journal of the Medical Association of Thailand $=$ Chotmaihet thangphaet 2008; 91(10): 1518-23.

33.Basuni AS, Ezz HA, Albirmawy OA. Preoperative peritonsillar infiltration of dexamethasone and levobupivacaine reduces pediatric post-tonsillectomy pain: a double-blind prospective randomized clinical trial. Journal of anesthesia 2013; 27(6): 844-9.

34.Guilfoyle MR, Helmy A, Duane D, Hutchinson PJ. Regional scalp block for postcraniotomy analgesia: a systematic review and meta-analysis. Anesthesia and analgesia 2013; 116(5): 1093-102.

35.Cata JP, Bhavsar S, Hagan KB, et al. Scalp blocks for brain tumor craniotomies: A retrospective survival analysis of a propensity match cohort of patients. Journal of clinical neuroscience: official journal of the Neurosurgical Society of Australasia 2018; 51: 46-51.

36.Sudheer PS, Logan SW, Terblanche C, Ateleanu B, Hall JE. Comparison of the analgesic efficacy and respiratory effects of morphine, tramadol and codeine after craniotomy. Anaesthesia 2007; 62(6): 55560.

37.McNicol ED, Ferguson MC, Hudcova J. Patient controlled opioid analgesia versus non-patient controlled opioid analgesia for postoperative pain. The Cochrane database of systematic reviews 2015; (6): CD003348. 
38.Sarin A, Litonius ES, Naidu R, Yost CS, Varma MG, Chen LL. Successful implementation of an Enhanced Recovery After Surgery program shortens length of stay and improves postoperative pain, and bowel and bladder function after colorectal surgery. BMC anesthesiology 2016; 16(1): 55.

39.Rakhman E, Shmain D, White I, et al. Repeated and escalating preoperative subanesthetic doses of ketamine for postoperative pain control in patients undergoing tumor resection: a randomized, placebocontrolled, double-blind trial. Clinical therapeutics 2011; 33(7): 863-73.

40.Urban MK, Ya Deau JT, Wukovits B, Lipnitsky JY. Ketamine as an adjunct to postoperative pain management in opioid tolerant patients after spinal fusions: a prospective randomized trial. HSS journal: the musculoskeletal journal of Hospital for Special Surgery 2008; 4(1): 62-5.

41.McNicol ED, Schumann R, Haroutounian S. A systematic review and meta-analysis of ketamine for the prevention of persistent post-surgical pain. Acta anaesthesiologica Scandinavica 2014; 58(10): 1199213.

42.Lavand'homme P, De Kock M, Waterloos $\mathrm{H}$. Intraoperative epidural analgesia combined with ketamine provides effective preventive analgesia in patients undergoing major digestive surgery. Anesthesiology 2005; 103(4): 813-20.

43.Maessen JM, Dejong CH, Kessels AG, von Meyenfeldt MF, Enhanced Recovery After Surgery G. Length of stay: an inappropriate readout of the success of enhanced recovery programs. World journal of surgery 2008; 32(6): 971-5.

44.Epstein AM, Stern RS, Tognetti J, et al. The association of patients' socioeconomic characteristics with the length of hospital stay and hospital charges within diagnosis-related groups. The New England journal of medicine 1988; 318(24): 1579-85.

45.Woodworth L, Romano PS, Holmes JF. Does Insurance Status Influence a Patient's Hospital Charge? Applied health economics and health policy 2017; 15(3): 353-62.

46.Yuill KA, Richardson RA, Davidson HI, Garden OJ, Parks RW. The administration of an oral carbohydrate-containing fluid prior to major elective upper-gastrointestinal surgery preserves skeletal muscle mass postoperatively-a randomised clinical trial. Clinical nutrition 2005; 24(1): 32-7.

47.Liu B, Wang Y, Liu S, et al. A randomized controlled study of preoperative oral carbohydrate loading versus fasting in patients undergoing elective craniotomy. Clinical nutrition 2018.

48.Smith MD, McCall J, Plank L, Herbison GP, Soop M, Nygren J. Preoperative carbohydrate treatment for enhancing recovery after elective surgery. The Cochrane database of systematic reviews 2014; (8): CD009161.

\section{Tables}


'able 1. Patient characteristics \& details of operations

\begin{tabular}{|c|c|c|c|c|c|c|}
\hline & Parameters & $\begin{array}{r}E R A \\
\quad(n\end{array}$ & $\begin{array}{l}\text { Group } \\
=64)\end{array}$ & & $\begin{array}{l}\text { ntrol } \\
\text { roup } \\
=65 \text { ) }\end{array}$ & $P$ \\
\hline ge (years) & & & & & & 0.723 \\
\hline$\square 40$ & patients, n (\%) & 38 & $59.4 \%$ & 36 & $55.4 \%$ & \\
\hline $40-65$ & patients, n (\%) & 26 & $40.6 \%$ & 29 & $44.6 \%$ & \\
\hline ender & & & & & & 0.713 \\
\hline Male & patients, n (\%) & 21 & $32.8 \%$ & 24 & $36.9 \%$ & \\
\hline Female & patients, n (\%) & 43 & $67.2 \%$ & 41 & $63.1 \%$ & \\
\hline MI (kg/m2) & $\begin{array}{l}\text { Median BMI, } \mathrm{kg} / \mathrm{m}^{2} \\
\text { (Range) }\end{array}$ & 24.1 & $\begin{array}{l}15.9- \\
29.6\end{array}$ & 24.7 & $\begin{array}{l}19.1- \\
28.4\end{array}$ & 0.395 \\
\hline SA classification & & & & & & 0.358 \\
\hline ASA I & n (\%) & 9 & $14.1 \%$ & 14 & $21.5 \%$ & \\
\hline ASA II & $\mathrm{n}(\%)$ & 55 & $85.9 \%$ & 51 & $78.5 \%$ & \\
\hline oncomitant diseases & & & & & & \\
\hline Cardiac/hypertension & n (\%) & 13 & $18.8 \%$ & 12 & $15.4 \%$ & 0.827 \\
\hline Smoker & $\mathrm{n}(\%)$ & 6 & $10.9 \%$ & 8 & $15.4 \%$ & 0.778 \\
\hline Liver/gall bladder & $\mathrm{n}(\%)$ & 7 & $10.9 \%$ & 4 & $7.7 \%$ & 0.364 \\
\hline Lung & $\mathrm{n}(\%)$ & 5 & $7.8 \%$ & 7 & $10.8 \%$ & 0.763 \\
\hline Diabetes mellitus & $\mathrm{n}(\%)$ & 11 & $6.3 \%$ & 7 & $7.7 \%$ & 0.321 \\
\hline Miscellaneous & n (\%) & 13 & $4.7 \%$ & 6 & $6.2 \%$ & 0.087 \\
\hline idication for surgery & & & & & & 0.516 \\
\hline & Meningioma, n (\%) & 38 & $59.4 \%$ & 30 & $46.2 \%$ & \\
\hline & $\begin{array}{l}\text { Vestibular schwannoma, } \\
\text { n (\%) }\end{array}$ & 7 & $10.9 \%$ & 9 & $13.8 \%$ & \\
\hline & $\begin{array}{l}\text { CPA Cholesteatoma, } \mathrm{n} \\
(\%)\end{array}$ & 6 & $9.4 \%$ & 8 & $12.3 \%$ & \\
\hline & Glioma, n (\%) & 13 & $20.3 \%$ & 18 & $27.7 \%$ & \\
\hline esion location & & & & & & 0.566 \\
\hline & Supratentorial superficial & 19 & $29.7 \%$ & 16 & $24.6 \%$ & \\
\hline & Supratentorial deep & 23 & $35.9 \%$ & 20 & $30.8 \%$ & \\
\hline & Infratentorial & 22 & $34.4 \%$ & 28 & $43.1 \%$ & \\
\hline
\end{tabular}

ASA: American Society of Anesthesiologists

CPA: cerebellopontine angle 


\section{Table 2. Primary outcome measures}

\begin{tabular}{|c|c|c|c|c|c|c|}
\hline \multirow{2}{*}{ Postoperative surgical pain, } & \multirow{2}{*}{$\begin{array}{c}\text { Parameters } \\
\text { Day of surgery }\end{array}$} & \multicolumn{2}{|c|}{$\begin{array}{c}\text { ERAS Group } \\
(\mathrm{n}=64)\end{array}$} & \multicolumn{2}{|c|}{$\begin{array}{l}\text { Control Group } \\
(\mathrm{n}=65)\end{array}$} & \multirow{2}{*}{$\begin{array}{c}P \\
0.477\end{array}$} \\
\hline & & 4.42 & $(1-8)$ & 4.71 & $(1-9)$ & \\
\hline \multirow[t]{4}{*}{ Mean (min-max) } & POD 1 & 3.12 & $(1-8)$ & 4.44 & $(1-9)$ & 0.010 \\
\hline & POD 2 & 2.85 & $(0-6)$ & 4.32 & $(0-8)$ & 0.002 \\
\hline & POD 3 & 2.32 & $(0-5)$ & 4.03 & $(0-6)$ & $<0.001$ \\
\hline & POD 4 & 2.25 & $(0-4)$ & 2.83 & $(0-6)$ & 0.273 \\
\hline \multirow{4}{*}{$\begin{array}{l}\text { POD1 Pain verbal NRS, } \\
\text { n (\%) }\end{array}$} & & & & & & $<0.001$ \\
\hline & $1-3$ & 44 & $68.8 \%$ & 23 & $35.4 \%$ & $<0.001$ \\
\hline & $4-7$ & 18 & $28.1 \%$ & 39 & $60.0 \%$ & $<0.001$ \\
\hline & $8-10$ & 2 & $3.1 \%$ & 3 & $4.6 \%$ & $>0.999$ \\
\hline $\begin{array}{l}\text { Postoperative pain duration } \\
\text { time, }\end{array}$ & & & & & & $<0.001$ \\
\hline \multirow[t]{4}{*}{ n $(\%)$} & $1-2 d$ & 35 & $54.7 \%$ & 13 & $20.0 \%$ & $<0.001$ \\
\hline & $2-3 d$ & 14 & $21.9 \%$ & 26 & $40.0 \%$ & 0.026 \\
\hline & $3-4 d$ & 13 & $20.3 \%$ & 23 & $35.4 \%$ & 0.056 \\
\hline & $>4 d$ & 2 & $3.1 \%$ & 3 & $4.6 \%$ & $>0.999$ \\
\hline
\end{tabular}

\section{Table 3. WHO classification of pain treatment}

Class Description

nonopioid analgesic drugs

II weak opioids (+ nonopioid analgesic drugs)

III strong opioids (+ nonopioid analgesic drugs) morphine, piritramid, meperidine

\section{Examples}

nonsteroidal antiinflammatory

drugs, acetaminophen tramadol, codeine 
Table 4. Secondary Outcome measures

\begin{tabular}{|c|c|c|c|c|c|c|}
\hline \multicolumn{2}{|c|}{ Parameter } & \multicolumn{2}{|c|}{ ERAS Group $(\mathrm{n}=64)$} & \multicolumn{2}{|c|}{$\begin{array}{c}\text { Control Group }(\mathrm{n}= \\
65)\end{array}$} & \multirow{3}{*}{$\begin{array}{c}\boldsymbol{P} \\
0.356\end{array}$} \\
\hline \multirow{4}{*}{$\begin{array}{c}\text { Analgesic } \\
\text { medication } \\
\text { administration }\end{array}$} & $\begin{array}{l}\text { Total pain } \\
\text { treatment }\end{array}$ & 15 & $23.4 \%$ & 22 & $33.8 \%$ & \\
\hline & $\mathrm{I}$ & 9 & $14.1 \%$ & 8 & $12.3 \%$ & \\
\hline & II & 3 & $4.7 \%$ & 9 & $13.8 \%$ & \\
\hline & III & 3 & $4.7 \%$ & 5 & $7.7 \%$ & \\
\hline \multirow{2}{*}{\multicolumn{2}{|c|}{$\begin{array}{l}\text { Median total hospital length } \\
\text { of stay from admission to } \\
\text { discharge (days, min, 1st Q, 3rd } \\
\text { Q, max) } \\
\text { Median post procedure length } \\
\text { of stay from end of procedure } \\
\text { to discharge (days, min, 1st Q, } \\
\text { 3rd Q, max) }\end{array}$}} & 10 & $4,8,12,29$ & 13 & $5,11,17,34$ & 0.004 \\
\hline & & 4 & $1,3,7,13$ & 7 & $3,5,11,28$ & 0.001 \\
\hline \multicolumn{2}{|c|}{$\begin{array}{l}\text { Total cost of hospitalization } \\
\text { (CNY, min, } 1 \text { st Q, 3rd Q, max) }\end{array}$} & 52424 & $\begin{array}{l}36652,46210 \\
68863,118965\end{array}$ & 64462 & $\begin{array}{l}45973, \\
59641 \\
82623 \\
139153\end{array}$ & 0.001 \\
\hline
\end{tabular}


Table 5. Postoperative Complications and Re-admission

\begin{tabular}{|c|c|c|c|c|c|}
\hline Parameter & & $\begin{array}{l}\text { Group (n } \\
64)\end{array}$ & Con & $\begin{array}{l}\text { Group (n } \\
\text { 55) }\end{array}$ & $P$ \\
\hline Postoperative fever & 9 & $14.1 \%$ & 14 & $21.5 \%$ & 0.358 \\
\hline Postoperative seizure & 3 & $4.7 \%$ & 2 & $3.1 \%$ & 0.680 \\
\hline Raised intracranial pressure & 0 & & 1 & & \\
\hline Recraniotomy & 0 & & 0 & & \\
\hline $\begin{array}{l}\text { Mental status changes (needs for } \\
\text { emergent imaging) }\end{array}$ & 0 & & 1 & & \\
\hline Diabetes insipidus & 0 & & 0 & & \\
\hline $\begin{array}{l}\text { Toxic epidermal necrolysis (due to } \\
\text { phenytoin) }\end{array}$ & 0 & & 0 & & \\
\hline Postoperative blood sugar $>200 \mathrm{mg} / \mathrm{dL}$ & 4 & $6.3 \%$ & 3 & $4.6 \%$ & 0.718 \\
\hline Nausea (moderate to severe) & 10 & $15.6 \%$ & 18 & $27.7 \%$ & 0.135 \\
\hline Use of anti-emetics & 10 & $15.6 \%$ & 20 & $30.8 \%$ & 0.060 \\
\hline $\begin{array}{l}\text { Re-admission within } 2 \text { weeks after } \\
\text { discharge }\end{array}$ & 0 & & 0 & & \\
\hline $\begin{array}{l}\text { Re-admission within } 4 \text { months after } \\
\text { discharge }\end{array}$ & 0 & & 0 & & \\
\hline
\end{tabular}

\section{Figures}




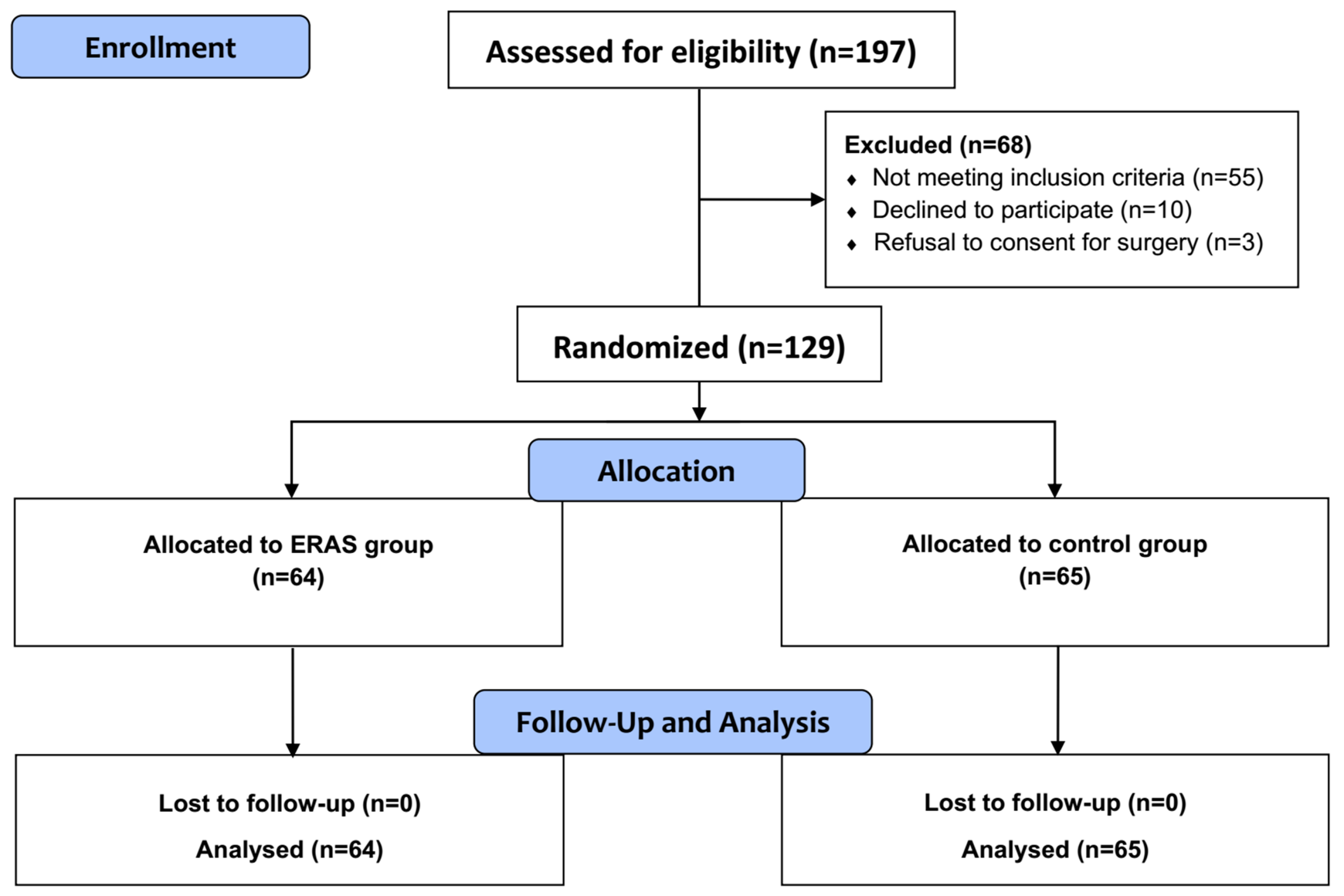

Figure 1

Flow diagram of CONSORT study design. Randomized controlled trial comparing ERAS group versus control group for elective craniotomies.

\section{Supplementary Files}

This is a list of supplementary files associated with this preprint. Click to download.

- Supplementaryfile3.ControlProtocolandERASProtocol.pdf

- Supplementaryfile2NeurosurgicalERASrecordchecklist.pdf

- CONSORT2010Checklist.doc

- Supplementaryfile1ResearchProtocol.pdf 